\title{
On the Value Added Taxation Status of National Postal Operators
}

\author{
PHILIPPE DE DONDER * \\ Toulouse School of Economics (GREMAQ-CNRS and IDEI) \\ HELMUTH CREMER \\ Toulouse School of Economics (GREMAQ, IDEI and Institut universitaire de France) \\ PAUL DUDLEY \\ Royal Mail Group \\ FRANK RODRIGUEZ \\ Royal Mail Group
}

\begin{abstract}
We study the pricing and welfare implications of changing the VAT status of the national postal operator (NPO) from exempt to rated. We build a model where the NPO offers both single-piece and bulk mail to customers, some of them VAT rated, others VAT exempt. We solve for the optimal Ramsey prices under monopoly and under access-based competition for bulk mail. We finally perform numerical simulations in order to determine how prices, volumes and welfare might be affected by the change in the NPO's VAT status, both under monopoly and under access-based competition for bulk mail.
\end{abstract}

\section{Introduction}

Within the European Union, the application of value added tax on postal services is a matter for the government of the member state. The state is required under the European Directive to ensure the provision of the universal postal service. The incumbent national postal operator faces universal service obligations including the daily collection and delivery of mail throughout the state with, in most cases, geographically uniform tariffs. In most countries, the incumbent national postal operator has been a monopolist, owned by the government and exempt from value added tax for the provision of the postal services. In some countries within Europe, the postal market has been opened up to competition so that the national postal operator is no longer a monopolist of postal services within the

\footnotetext{
* Contact author: 21, allée de Brienne, 31000 Toulouse, France. Email: dedonder@cict.fr An earlier version of this paper has been presented at the Fifth conference on "Regulation, Competition and Universal Service in the Postal Sector", Toulouse, March 2008. We thank participants and especially our discussant, Georges Houpis, for useful comments and suggestions. The analysis contained in this paper reflects the views of the authors and may not necessarily be those of Royal Mail Group.
} 
state and in some countries the national postal operator has transferred from public to private ownership. The application of value added tax for postal services in the presence of such change is important in understanding the development of the postal markets in Europe. ${ }^{1}$

The application of value added tax (VAT) is of interest because either the postal operator or customer may be VAT exempt or VAT rated. For the postal operator, if it is exempt from charging VAT on postal services it is unable to recover VAT they pay on inputs so these unrecovered tax payments enter their cost base in forming the prices of their postal services. On the other hand, if a postal operator is required to charge VAT on the postal services they offer, which is generally the case for postal operators other than the national postal operator, then they are rated for VAT purposes and are able to recover input tax. A similar distinction holds for the customers of postal services, some of them being VAT exempt (such as financial services and insurance firms in the UK) while others are VAT rated. Tax incidence and prices then differ depending on whether the postal operator and customer is VAT exempt or VAT rated. For instance, extending a VAT exemption to the national postal operator but not to its competitors may give to the former a pricing advantage when dealing with VAT exempt customers, and a disadvantage when dealing with VAT rated customers.

In this paper, we explore some of the issues relating to the application of value added tax under alternative objective functions, initially where the incumbent is a monopolist and then where it operates in a market that is open to competition in the provision of some upstream services, through entrants accessing the incumbent's downstream services. In addition to the tax incidence and prices, we also consider the welfare implications of these various cases. In our model, the national operator offers two end-to-end (E2E) products: a single-piece product and a business mail product. The business mail product is offered to both VAT rated and VAT exempt customers. The entrants, when introduced, act as a competitive fringe offering a bulk mail product that is an (imperfect) substitute to the bulk mail offered by the national operator. The national operator also sells access to its delivery areas to the entrants, thereby selling an intermediate good as well as the two end-to-end products. While the national operator is either VAT rated or VAT exempt, the entrants are assumed to be VAT rated throughout. As such, the model for this paper develops that of De Donder et al (2006) to explore the issues of value added tax within postal services. To the best of our knowledge, this is the first paper looking at the implications of the change in VAT status of operators in the postal market using an analytical model. ${ }^{2}$

The paper proceeds as follows. Our model is set out further in section 2, first for the monopoly case and then when bulk mail is opened to competition. In this section, we provide analytically the optimal Ramsey pricing formulas for the national operator. In

\footnotetext{
${ }^{1}$ The postal sector is unusual in that it is the only network industry for which the 2006 VAT Directive mentions (in its Article 132) a "public service exemption" for VAT for the national operator. The other two public service exemptions are hospital services "by bodies governed by public laws, or under social conditions comparable with these", and old people's homes "by bodies governed by public laws or recognized as being devoted to social wellbeing".

${ }^{2}$ See Auerbach and Hines (2001) for a general presentation of the economic impact of value added taxation. De Donder et al (2009) builds on the analytical framework developed in this paper and is exclusively numerical. This sequel uses the same calibration assumptions as used here and extends the numerical simulations performed in the second part of the current paper to the cases where the entrants bypass the incumbent's delivery network and where different VAT rates are charged on different postal goods. We come back to this paper in the concluding section.
} 
order to assess the impact of the VAT status of this operator on volumes and welfare, we then calibrate the model in Section 3. Section 4 presents, for the monopolist and competition cases, some numerical results for the second best welfare maximizing case and, by contrast, a case with the minimum single-piece price that enables the national operator to break-even. Section 5 concludes.

\section{The model}

We first describe the model when the national postal operator (NPO) has a monopoly before moving to the case where it faces competition on the bulk mail market.

\subsection{Monopoly}

We start the analysis with a single NPO (variables denoted with the superscript $I$ ) that offers both single-piece mail (whose quantity is denoted by $x$ ) and bulk mail (whose quantity is denoted by $y^{I}$ ) to a single delivery area. We denote by $q$ the before-tax price of single-piece mail and by $p^{I}$ the before-tax price of bulk mail. There is a single VAT rate paid on all goods (non-labor inputs and outputs) which is denoted by $t$. We will consider both the case where the NPO is VAT exempt and where it is VAT rated.

The demand for single-piece mail is assumed to be independent from the demand for bulk mail. ${ }^{3}$ All customers of single-piece mail are VAT exempt. ${ }^{4}$ In the case where the NPO is also VAT exempt, their demand for single-piece mail is given by $x(q)$. If the NPO is VAT rated, their demand is $x(q(1+t))$. We distinguish two kinds of bulk mail customers: those who are VAT rated (denoted with subscript $R$ ) and those who are not (subscript $N$ ). VAT exempt buyers care about the after-tax price of the good while the VAT rated ones care about the before-tax price (because they reclaim the VAT they pay on this good, which is an input in their own production process). The postal operator charges the same before-tax price $p^{I}$ to the two types of customers. ${ }^{5}$ The total demand for NPO bulk mail is given by

$$
y^{I}\left(p^{I}\right)=y_{R}^{I}\left(p^{I}\right)+y_{N}^{I}\left(p^{I}(1+t)\right)
$$

if the NPO is VAT rated, and by

$$
y^{I}\left(p^{I}\right)=y_{R}^{I}\left(p^{I}\right)+y_{N}^{I}\left(p^{I}\right)
$$

if not.

\footnotetext{
${ }^{3}$ This assumption is reasonable provided that the difference between single-piece mail price and bulk mail price is at least equal to the preparation cost that bulk mail users have to incur. Since this constraint is not binding in all Ramsey problems studied in section 4, we do not formally introduce it in the equations below. ${ }^{4}$ In the main, customers of single-piece mail are households which by definition do not sell goods and services and so neither charge VAT nor reclaim input tax; or they are small businesses whose level of business turnover is below that at which they are required to levy VAT and so again neither charge the tax nor are able to recover input tax.

${ }^{5}$ This may be due to the unobservability of the tax status of customers, to transaction costs in implementing different prices, or to a mandate imposed by a regulator.
} 
The NPO faces three kinds of costs: fixed costs, upstream costs and delivery costs. The fixed cost is denoted by $F$, with a fraction $\alpha_{F}$ that is non-labor costs - that is, on which the NPO pays VAT. This fixed cost reflects the fact that the NPO is subject to a universal service obligation which, among other things, necessitates the building of a delivery network providing daily services to the totality of the country. We denote by $c_{x}$ (respectively, $c_{y}^{I}$ ) the constant marginal upstream cost for single-piece mail (respectively, bulk mail), and we assume that $c_{x}>c_{y}^{I}$. We denote by $d^{I}$ the constant marginal delivery cost for both single-piece and bulk mail. Finally, $\alpha^{I}$ denotes the fraction of the upstream and delivery costs that is non-labor - that is, on which the NPO pays VAT.

The costs faced by the NPO depend on its VAT status. The NPO pays VAT on its nonlabor inputs whatever its VAT status. If the NPO is VAT exempt, it does not charge VAT to its customers and can not reclaim the VAT paid on inputs. If the NPO is VAT rated, it charges VAT to its customers and reclaims the VAT it has paid on inputs. In the case the NPO is VAT exempt (denoted with a subscript $N$ ), its cost of providing $x$ units of singlepiece mail and $y^{I}$ units of bulk mail is denoted by

$$
C_{N}\left(x, y^{I}\right)=F\left(1+\alpha_{F} t\right)+\left(1+\alpha^{I} t\right)\left(\left(c_{x}+d^{I}\right) x+\left(c_{y}^{I}+d^{I}\right) y^{I}\right)
$$

where $\alpha_{F} t F$ is a fixed amount of VAT paid by the NPO irrespective of its volume of output of postal services while

$$
t \alpha^{I}\left(\left(c_{x}+d^{I}\right) x+\left(c_{y}^{I}+d^{I}\right) y^{I}\right)
$$

measures the variable part of VAT the NPO pays.

On the other hand, if the NPO is VAT rated, it can recoup the VAT paid on inputs, and its cost function is given by

$$
C_{R}\left(x, y^{I}\right)=F+\left(c_{x}+d^{I}\right) x+\left(c_{y}^{I}+d^{I}\right) y^{I} .
$$

We obviously have that

$$
C_{N}\left(x, y^{I}\right)>C_{R}\left(x, y^{I}\right)
$$

The (net of tax) NPO's profit is given by

$$
\Pi_{N}\left(q, p^{I}\right)=q x(q)+p^{I}\left[y_{R}^{I}\left(p^{I}\right)+y_{N}^{I}\left(p^{I}\right)\right]-C_{N}\left(x(q), y^{I}\left(p^{I}\right)\right)
$$

if the NPO is VAT exempt and

$$
\begin{array}{r}
\Pi_{R}\left(q, p^{I}\right)=\quad q x(q(1+t))+p^{I}\left[y_{R}^{I}\left(p^{I}\right)+y_{N}^{I}\left(p^{I}(1+t)\right)\right] \\
-C_{R}\left(x(q(1+t)), y_{R}^{I}\left(p^{I}\right)+y_{N}^{I}\left(p^{I}(1+t)\right)\right)
\end{array}
$$


if it is VAT rated. This illustrates the impact on the NPO's profit of changing its VAT status from exempt to rated, while keeping before-tax prices constant. On the output side, this move decreases the amount demanded by single-piece buyers (who are all VAT exempt) and by VAT exempt bulk mail customers (the other bulk mail customers are not affected since they reclaim the VAT they pay on inputs). This impact on profit is thus negative. On the input side, the NPO can now reclaim the VAT it is paying on inputs. This impact on profit is positive. The sign of the net impact is ambiguous and depends on demand elasticities: if the demand by VAT exempt customers were totally inelastic, the first impact would disappear and the net effect would be positive. The larger the demand elasticity of those customers, the lower $\Pi_{R}\left(q, p^{I}\right)-\Pi_{N}\left(q, p^{I}\right)$, for given prices $q$ and $p^{I}$.

\subsubsection{Optimal pricing formulas with VAT exempt NPO}

We first study a Ramsey-type objective for the social planner, who maximizes total welfare in the postal economy subject to the NPO breaking even. Total welfare is made up of consumer surplus, NPO's profit and VAT proceeds raised in the postal sector. We assume that the planner values the VAT proceeds using an exogenous cost of public funds, denoted by $\mu$. With a VAT exempt NPO, the optimization problem is

$$
\begin{aligned}
\max _{q, p^{I}} & W_{N}^{M}=C S_{x}(q)+C S_{N}^{M}\left(p^{I}\right)+C S_{R}^{M}\left(p^{I}\right)+\Pi_{N}\left(q, p^{I}\right)+(1+\mu) V A T_{N}^{M}\left(q, p^{I}\right) \\
& \text { such that } \Pi_{N}\left(q, p^{I}\right) \geq 0
\end{aligned}
$$

where $C S_{x}(q)$ measures the net consumer surplus of single-piece mail buyers and $C S_{N}^{M}($. (respectively, $C S_{R}^{M}($.$) ) measures the net consumer surplus of the VAT exempt$ (respectively, VAT rated) bulk mail buyers. The parameter $\lambda$ is the Lagrange multiplier of the NPO budget constraint and measures the shadow cost of this constraint in terms of social welfare $W_{N}^{M}$.

When the NPO is VAT exempt, the amount of VAT proceeds in the postal sector is given by

$$
\operatorname{VAT}_{N}^{M}\left(q, p^{I}\right)=t \alpha_{F} F+t \alpha^{I}\left[\left(c_{x}+d^{I}\right) x(q)+\left(c_{y}^{I}+d^{I}\right)\left(y_{N}^{I}\left(p^{I}\right)+y_{R}^{I}\left(p^{I}\right)\right)\right] .
$$

The FOC with respect to $q$ is given by the Ramsey-like formula

(2)

$$
\frac{q-\left[\left(1+\frac{\lambda-\mu}{1+\lambda} \alpha^{I} t\right)\left(c_{x}+d^{I}\right)\right]}{q}=\frac{\lambda}{1+\lambda} \frac{1}{\varepsilon_{x}}
$$

where $\varepsilon_{x}$ denotes the (absolute value of the) demand price elasticity of single-piece mail. The reader will recognize the Ramsey rule, with the mark-up over marginal cost inversely proportional to the price elasticity of demand. Formula (2) differs from the traditional Ramsey rule in that it makes use of a modified marginal cost of the firm (the term in 
brackets) rather than the effective marginal cost for society, $c_{x}+d^{I}$. This formulation conforms to intuition, since the NPO does not charge VAT on single-piece mail (so that consumer and producer prices of this good are the same) but pays VAT on its inputs (so that VAT affects the NPO's costs). Other things equal, a larger value of $\mu$ decreases this modified marginal cost of the firm and thus calls for a lower value of $q$. The intuition is straightforward: a planner putting more weight on tax proceeds (a higher $\mu$ ) is induced to lower the price in order to increase volumes and generate more VAT proceeds when the NPO buys its inputs. If $\mu=-1$, the planner does not take into account tax proceeds and the relevant marginal cost is the after-tax one for the firm. If $\mu=0$ (zero cost of public funds), the tax part of the marginal cost is deflated by $\lambda /(1+\lambda)$. If $\lambda=\mu$, the relevant marginal cost is the before-tax one, $c_{x}+d^{I}$, as the concerns for the NPO breaking even and the cost of public funds neutralize each other. We then get back to the classical Ramsey formulation when $\lambda=\mu$. As usual, a larger value of $\lambda$ is associated with a larger value of the equilibrium price $q$.

The FOC for the bulk mail price is obtained similarly:

$$
\frac{p^{I}-\left[\left(1+\frac{\lambda-\mu}{1+\lambda} \alpha^{I} t\right)\left(c_{y}^{I}+d^{I}\right)\right]}{p^{I}}=\frac{\lambda}{1+\lambda} \frac{1}{\varepsilon_{y}}
$$

where $\varepsilon_{y}$ denotes the direct price elasticity of (total) bulk mail demand $y^{I}\left(p^{I}\right)$.

\subsubsection{Optimal pricing formulas with VAT rated NPO}

When the NPO is VAT rated, the planner's objective is given by

$$
\begin{aligned}
\max _{q, p^{I}} W_{R}^{M}= & C S_{x}(q(1+t))+C S_{N}^{M}\left(p^{I}(1+t)\right)+C S_{R}^{M}\left(p^{I}\right) \\
& +\Pi_{R}\left(q, p^{I}\right)+(1+\mu) V A T_{R}^{M}\left(q, p^{I}\right)
\end{aligned}
$$

such that $\Pi_{R}\left(q, p^{I}\right) \geq 0$,

with $\lambda$ denoting the Lagrange multiplier of the profit constraint. Now that the NPO is VAT rated, both single-piece mail customers and a fraction of bulk mail customers (those who are not rated) pay VAT. As for VAT rated buyers of bulk mail, they do not pay VAT themselves but rather charge VAT to their final customers. We make the simplifying assumption that the final amount of VAT paid by their final customers is not affected by the bulk mail price they pay. ${ }^{6}$ We then have that

\footnotetext{
${ }^{6}$ This is the case for instance if postal services represent a small fraction of the inputs of bulk mail buyers, so that their own output price is not affected significantly by variations in bulk mail price. The alternative to this simplifying assumption would require us to model the demand function for the final goods and services sold by VAT rated buyers of bulk mail. This would complicate the model and introduce a further set of assumptions related to these demand functions.
} 


$$
\operatorname{VAT}_{R}^{M}\left(q, p^{I}\right)=t\left[q x(q(1+t))+p^{I} y_{N}^{I}\left(p^{I}(1+t)\right)\right]
$$

The FOC with respect to $q$ is then given by

(6)

$$
\frac{q\left(1+\frac{1+\mu}{1+\lambda} t\right)-\left(c_{x}+d^{I}\right)}{q}=\frac{\lambda+\mu t}{1+\lambda} \frac{1}{\varepsilon_{x}}
$$

Unlike (2), the Ramsey rule is expressed here in terms of the difference between a modified price and the resource cost for society. This formulation conforms to intuition, since the NPO charges VAT on single-piece mail (so that consumer and producer prices of this good differ) but recoups VAT on its inputs (so that VAT does not affect directly the NPO's costs). The impact of $\mu$ on the optimal value of $q$ is more complex than when the NPO is VAT exempt, since $\mu$ is present both on the left-hand side and on the right-hand side of (6), with opposite impacts on the optimal value of $q$. This is because VAT proceeds are obtained from taxing single-piece mail sales revenues, and not from taxing inputs. With a VAT exempt NPO, tax proceeds are always decreasing in $q$, since a higher price decreases both the volume and the value of the inputs bought by the NPO. When the NPO is VAT rated, an increase in $q$ does not always decrease VAT proceeds, since the value of sales may increase even if their volume decreases. On the other hand, increasing $\lambda$ is as usual associated with a larger optimal value of $q$. Observe that, in the special case where $\lambda=\mu$, equation (6) simplifies to the classical Ramsey formula in terms of after-tax price $q(1+t)$. We obtained a similar result (but in terms of before-tax price $q$ ) in the case where the NPO is VAT exempt.

The FOC with respect to $p^{I}$ is more complex:

$$
\begin{aligned}
& \lambda y_{R}^{I}(.)+(1+\lambda)\left(p^{I}-\left(c_{y}^{I}+d^{I}\right)\right) \frac{\partial y_{R}^{I}(.)}{\partial p^{I}} \\
& +(\lambda+\mu t) y_{N}^{I}(.)+(1+\lambda)(1+t)\left(p^{I}\left(1+\frac{1+\mu}{1+\lambda}\right)-\left(c_{y}^{I}+d^{I}\right)\right) \frac{\partial y_{N}^{I}(.)}{\partial p^{I}} \\
= & 0 .
\end{aligned}
$$

The complexity of the formula is due to the fact that a single price, $p^{I}$, affects the bulk mail demand coming both from VAT rated and from VAT exempt customers, with different consequences on VAT proceeds. The first line in (7) denotes the impact on welfare through variations in the VAT rated market while the second line represents the impact in the VAT exempt market. If the NPO were able and allowed to post different prices on these two markets, say $p_{R}^{I}$ and $p_{N}^{I}$, the optimal price formula on the VAT rated market would be 
(8) $\frac{p_{R}^{I}-\left(c_{y}^{I}+d^{I}\right)}{p_{R}^{I}}=\frac{\lambda}{1+\lambda} \frac{1}{\varepsilon_{R}}$

while the price formula in the VAT exempt market would be

$$
\frac{p_{N}^{I}\left(1+\frac{1+\mu}{1+\lambda} t\right)-\left(c_{y}^{I}+d^{I}\right)}{p_{N}^{I}}=\frac{\lambda+\mu t}{1+\lambda} \frac{1}{\varepsilon_{N}}
$$

with $\varepsilon_{i}$ the direct price elasticity of bulk mail demand among VAT rated customers $(i=R)$ and VAT exempt customers $(i=N)$.

The optimal price in the VAT rated market is given by the usual Ramsey formula (8). The cost of public funds does not play any role, since $p_{R}^{I}$ does not affect the VAT proceeds as given by (5). The optimal price formula in the VAT exempt market is similar to the corresponding formula for the single-piece mail product, given by (6).

Since we assume that the same price has to be posted on both markets, the optimal pricing formula is given by the more complex equation (7).

In each case (NPO VAT rated or not), the Ramsey optimization program generates a pair of prices $\left(q, p^{I}\right)$ that are consistent with the NPO breaking-even. There of course exist other pairs of prices consistent with the NPO breaking-even. Among these pairs, a particularly interesting one corresponds to the minimum value of the single-piece mail price. Indeed, one can make the point that regulators tend to care a lot about the value of this price since it is the most visible to citizens/voters (see Panzar (2004)). The problem the planner solves in that case is to find ${ }^{7}$

(10) $\min q$ such that $\Pi_{i}\left(q, p^{I}\right) \geq 0, i=N, R$.

\subsection{Competition with access only}

We now enrich our analysis by introducing entrants (denoted by $E$ ) that compete with the NPO by offering a bulk mail product to both VAT rated and VAT exempt customers. The bulk mail product offered by entrants is an (imperfect) substitute to the good provided by the NPO. The entrants are VAT rated: they charge VAT to customers and reclaim any VAT they pay on inputs. The quantity of bulk mail sold by entrants is denoted by $y^{E}$. As we have seen with the NPO monopolist, the demand by VAT rated customers depends on before-tax prices. Denoting the entrants's before-tax price for bulk mail by $p^{E}$, we have that the demand by VAT rated customers for NPO (respectively, entrants') bulk mail is given by $y_{R}^{I}\left(p^{I}, p^{E}\right)$ (respectively, $\left.y_{R}^{E}\left(p^{I}, p^{E}\right)\right)$. The demands by VAT exempt customers

\footnotetext{
${ }^{7}$ As explained in footnote 3, we also impose the constraint that $q \geq p^{I}+k$, where $k$ represents the preparation cost borne by all users of bulk mail. Unlike for the Ramsey formulas studied above, this constraint is binding for the formulation (10) with our calibration assumptions.
} 
depends on after-tax prices. Assuming that the NPO is VAT exempt, we have demand functions $y_{N}^{I}\left(p^{I}, p^{E}(1+t)\right)$ and $y_{N}^{E}\left(p^{I}, p^{E}(1+t)\right)$. In the case where the NPO is also VAT rated, like the entrant, the demands are given by $y_{N}^{I}\left(p^{I}(1+t), p^{E}(1+t)\right)$ and $y_{N}^{E}\left(p^{I}(1+t), p^{E}(1+t)\right)$. Total demand for NPO (respectively, entrants') bulk mail is denoted by $y^{I}\left(p^{I}, p^{E}\right)$ (respectively, by $\left.y^{E}\left(p^{I}, p^{E}\right)\right)$.

To summarize, we have that, if the NPO is VAT exempt,

$$
\begin{aligned}
& y^{I}\left(p^{I}, p^{E}\right)=y_{R}^{I}\left(p^{I}, p^{E}\right)+y_{N}^{I}\left(p^{I}, p^{E}(1+t)\right) \\
& y^{E}\left(p^{I}, p^{E}\right)=y_{R}^{E}\left(p^{I}, p^{E}\right)+y_{N}^{E}\left(p^{I}, p^{E}(1+t)\right),
\end{aligned}
$$

while, if the NPO is VAT rated, we have

$$
\begin{aligned}
& y^{I}\left(p^{I}, p^{E}\right)=y_{R}^{I}\left(p^{I}, p^{E}\right)+y_{N}^{I}\left(p^{I}(1+t), p^{E}(1+t)\right), \\
& y^{E}\left(p^{I}, p^{E}\right)=y_{R}^{E}\left(p^{I}, p^{E}\right)+y_{N}^{E}\left(p^{I}(1+t), p^{E}(1+t)\right) .
\end{aligned}
$$

As for costs, we assume that entrants have no fixed cost, ${ }^{8}$ a constant marginal upstream cost of $c^{E}$ and are obliged to buy access to the NPO delivery network at a constant (net of tax) unit cost (access charge) of $a$. One unit of bulk mail necessitates one unit of access.

We assume that entrants behave like a competitive fringe. The before-tax price charged by entrants is then

$$
p^{E}=a+c^{E}
$$

Whether the NPO is VAT exempt has no direct impact on this price formula since entrants behave like a competitive fringe, and since the "true" marginal cost of a VAT rated entrant is not affected by whether the entrant has paid VAT on (part of) its inputs.

In the Appendix, we present an extended analytical study of this model. In particular, we provide the expressions for the optimal second-best prices of the NPO when it is VAT exempt and when it is VAT rated. We summarize here the main results obtained. First, the formulas for the optimal single-piece price are not affected by the presence of entrants on the bulk mail markets, and are still given by equation (2) if the NPO is VAT exempt and by (6) if it is VAT rated. Although the formulas are the same, the optimal value of $q$ will typically differ because the equilibrium value of $\lambda$ differs. In order to assess whether the optimal single-piece price is lower or higher in the presence of bulk mail competition, we will have to resort to numerical simulations.

Second, we now have two types of prices to determine in the bulk mail market: $p^{I}$ and $a$ - that is, the prices of both the final good and the intermediate good sold by the NPO. The optimality formulas for these two prices are closely linked, with one optimal price depending upon the other, as is usual in the literature (see Armstrong (2002) and De Donder (2006)). Third, the optimal prices when the NPO is VAT rated are especially

\footnotetext{
${ }^{8}$ The absence of fixed cost is due to the fact that entrants, unlike the NPO, are not subject to a universal service obligation. In the calibrations, we assume that the absence of fixed costs for entrants translates into higher marginal (upstream and delivery) costs than for the NPO.
} 
complex because they take into account both VAT rated and VAT exempt customers. To simplify these formulations, we assume as in the previous section that the NPO can charge prices that vary according to the VAT status of the customer. Observe that this is also the case for the access charge even when the NPO is VAT exempt, because access is sold to VAT rated entrants whose clientele encompasses both VAT rated and VAT exempt customers.

In the case where the NPO is VAT rated and where its final customers are VAT rated, the optimal price formulas correspond exactly to those developed in the literature. In other words, as in section 2.1.2 above, the VAT rate $t$ and the cost of public funds $\mu$ have no impact on optimal prices. In the other cases, the optimality formulas are much more complex. We analyze them in the Appendix and we show how the optimal bulk mail pricing formulas differ from their monopoly counterparts. The main picture that emerges is that the adjustments to be made to optimal formulas to take account of changes in VAT status resemble those made in the monopoly case.

First-order conditions give us important insights regarding the determinants of optimal prices. In order to go beyond and focus on price levels (as opposed to pricing rules), quantities and welfare levels, we have to calibrate our model and to run numerical simulations. These simulations allow us to look at several dimensions. First, they allow us to study the tax incidence effects of changes in the VAT status of the NPO, by determining how pre- and post-tax prices are affected by these changes. More generally, they allow us to identify potential impacts on economic welfare and its distribution from a change in VAT status, and to check whether our results are robust to the introduction of access-based bulk mail competition. Finally, they allow to compare the results obtained with different objectives (such as the minimization of the single-piece price, or the second best objective discussed above), for any given VAT status of the NPO and market conditions. We now turn to the calibration of the model.

\section{Calibration}

Our calibration assumptions are the same as in De Donder et al (2006), but without distinction between delivery zones. Note that, as in that paper, the assumptions used here do not represent the position in a particular NPO. Rather they are stylized and applied to illustrate the effects within the model given the complexity of analytical solutions to the formal model set out in section 2 . We start from the hypothetical situation where the VAT exempt NPO does not face any entrants and posts a price of 0.50 for the single-piece product and 0.40 for its bulk mail product. Total quantities sold at those prices are, respectively, 2 billion and 8 billion items. We assume that VAT rated and VAT exempt consumers have the same demand function

$$
y_{R}^{I}\left(p^{I}\right)=y_{N}^{I}\left(p^{I}\right)
$$

so that they both demand 4 billion items for a 0.40 bulk mail price. The direct price elasticities are -0.2 for single-piece mail and -0.4 for bulk mail at these prices. Finally, we calibrate linear demands based on these quantities, prices and elasticities.

We need further information to calibrate the demand functions for bulk mail products when the market is opened to competition. We use two types of information: the extent of 
entry for different price configurations and the substitutability between the two bulk mail products for consumers. We assume that entrants would capture $10 \%$ of the total market for bulk mail if both bulk mail products had the same price and $50 \%$ of the market if entrants were to offer a $20 \%$ price discount over the NPO. As for substitution between those products, we assume that the displacement ratio is set at 0.75 which means that three quarters of the quantities sold by entrants are displaced from the NPO, while one quarter represents additional volumes sold in the sector. We make the same assumptions for bulk mail demand emanating from VAT rated and VAT exempt customers.

The NPO constant marginal upstream cost (before tax) is $c_{x}=0.173$ for single-piece mail $^{9}$ and $c_{y}^{I}=0.115$ for bulk mail. The NPO constant marginal delivery cost (for all kinds of mail), $d^{I}$ is 0.116 . The share of fixed cost that is non-labor is $\alpha_{F}=0.4$ while the corresponding fraction for variable costs is $\alpha^{I}=0.2$. The VAT rate $t$ is $20 \%$. The (before tax) fixed cost $F$ equals $1.556 \mathrm{bn}$ so that the PO breaks even in the hypothetical monopoly situation ( $F$ equals $40 \%$ of revenue of $4.2 \mathrm{bn}$ ). An entrant does not face any fixed cost but we assume that this results in higher variable upstream and delivery costs than the NPO. Accordingly, an entrant's before tax upstream cost, $c^{E}$, is set at 0.144 , its delivery cost at 0.183 . The preparation cost $k$ borne by all users of bulk mail is set at 0.06

\section{$4 \quad$ Numerical results}

We first look at the monopoly case before turning to the simulations with access-based competition for the bulk mail product.

\subsection{Monopoly}

Table 1 shows the results of the monopolist NPO. The first three columns of figures relate to the VAT exempt monopolist. The first column shows the calibration used. With no VAT applied to the NPO the pre and post-tax prices are the same, at 0.50 for the single-piece and 0.40 for the bulk mail piece. The calibration assumptions correspond to the equiproportional mark-up (EPMU) solution, with the same mark-up over marginal cost posted for both the single-piece mail and bulk mail. For these prices, $80 \%$ of volumes are bulk mail (40\% from VAT exempt customers and 40\% for VAT rated ones), and the remaining $20 \%$ is single-piece mail. Given the stylized assumptions used in the calibration set out in section 3, around $28 \%$ of the NPO's costs are subject to VAT (this is a weighted average of the percentage of non-labor fixed costs, $40 \%$, and of non-labor variable costs, $20 \%$ ). No VAT is paid by customers and the NPO pays VAT of 0.221 bn through its input costs. Total consumer surplus is $6.500 \mathrm{bn}$, while the NPO's profit equals zero by construction. The last row in the Table gives the value of the objective, total welfare - that is, the sum of customer surplus, NPO's profit and of $(1+\mu)$ times VAT proceeds, with $\mu=0.3$ being the exogenous cost of public funds. ${ }^{10}$ This equals $6.788 \mathrm{bn}$ in the calibrated simulation.

\section{VAT exempt NPO VAT rated NPO}

\footnotetext{
${ }^{9}$ This value corresponds to an after-tax cost of 0.18 (the value used in De Donder et al (2006)) once a ( $t=20 \%$ ) VAT rate has been imposed on the $\left(\alpha^{I}=20 \%\right)$ fraction of the upstream cost that is non-labor.

${ }^{10}$ Most estimates of the cost of public funds, in developed countries are in the range of 0.2 to 0.3 .
} 


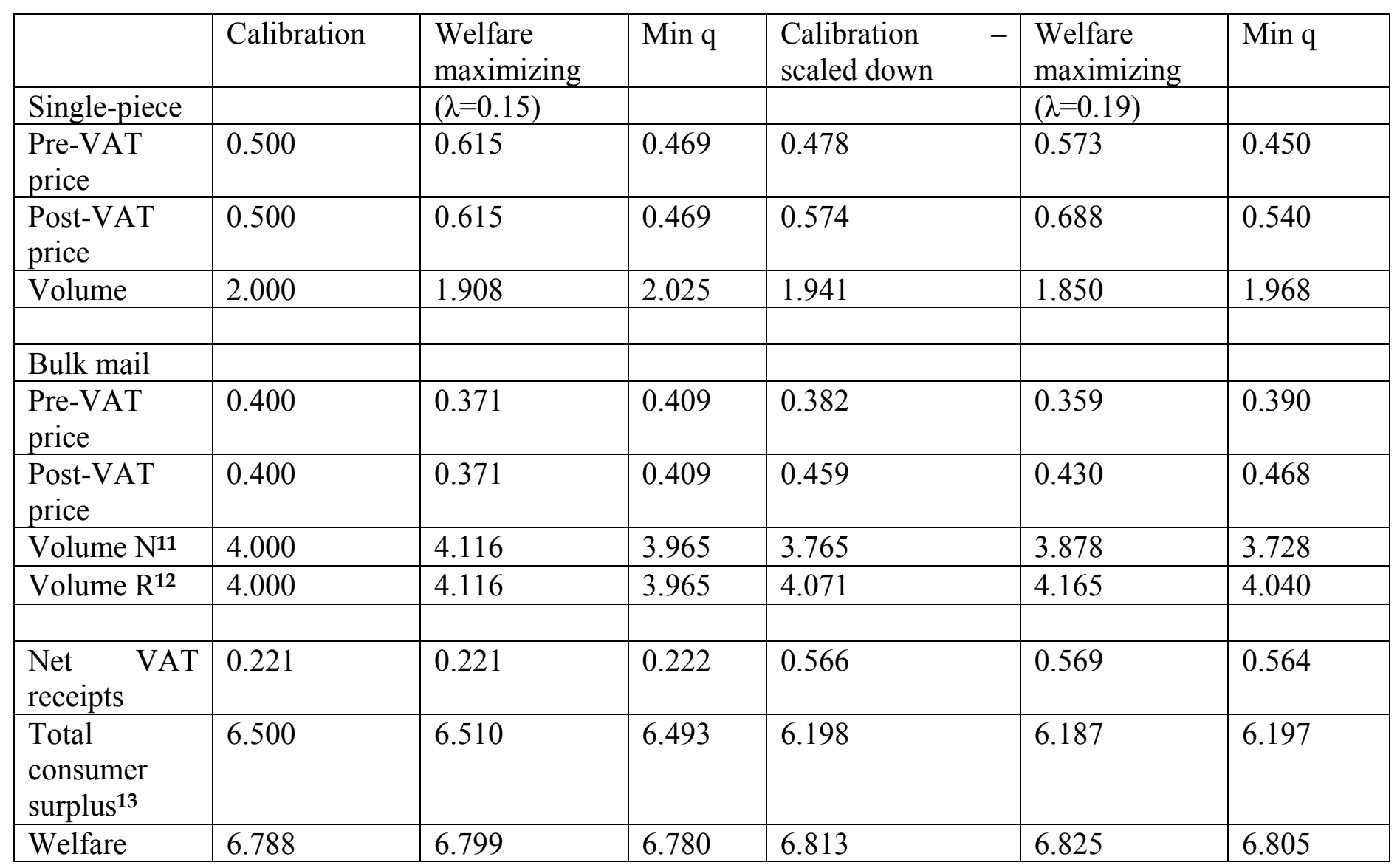

Table 1: Allocations with the monopolist NPO $^{14}$

The second best welfare maximizing results corresponding to program (1) are shown in the second column of figures. The value of the Lagrange multiplier of the break-even constraint, $\lambda$, is lower than the exogenous value of the cost of public funds, $\mu$. Demand elasticity is larger for bulk mail than for single-piece mail, so that Ramsey prices under program (1) are lower than EPMU for the first category of mail, and larger for the second. The single-piece price (given by equation (2)) increases to 0.615 , and its demand reduces from $2.00 \mathrm{bn}$ items to $1.908 \mathrm{bn}$. The bulk mail price (given by equation (3)) reduces from 0.40 to 0.371 , and its demand increases from $8.00 \mathrm{bn}$ to $8.25 \mathrm{bn}$ items. The NPO pays VAT of $0.221 \mathrm{bn}$ through its input costs. Single-piece customers' surplus decreases (compared to the calibration allocation), while bulk mail customers' surplus increases. As expected from the comparative nature of the two programs, the weighted sum of customers' surpluses and VAT proceeds increases (since this is what is maximized in this simulation) but only slightly. Observe that total customers' surplus is also slightly higher than in the calibration simulation.

The third column reports the solution of optimization problem (10). Observe that the constraint that $p^{I} \leq q-k$, with $k=0.06$, is binding. The minimum single-piece mail price decreases to 0.469 , and its demand increases to $2.025 \mathrm{bn}$. The bulk mail price increases to

\footnotetext{
${ }^{11} \mathrm{~N}=$ non VAT rated or VAT exempt customers

${ }^{12} \mathrm{R}=\mathrm{VAT}$ rated customers

${ }^{13}$ NPO's profit is zero by construction in all scenarios considered.

${ }^{14}$ Prices are expressed in $€$, volumes in billion items, VAT receipts, surplus and welfare in billion euros.
} 
0.409 - consistent with a minimum margin of 0.06 between the bulk mail and single-piece price - to recover the shortfall from the lower single-piece price; the bulk mail demand reduces to 7.93bn items, split equally between (VAT rated) $R$ and (VAT exempt) $N$ customers. The NPO pays VAT of $0.222 \mathrm{bn}$ through its input costs, total consumer surplus reduces to $6.493 \mathrm{bn}$ and the total welfare reduces to $6.78 \mathrm{bn}$. The welfare is marginally lower in this case as the single-piece price is set to a minimum value and results in the bulk mail price increasing to reach break-even.

The break-even results involve a range of single-piece prices between 0.469 and 0.615 . However, no VAT is charged on these prices, nor the bulk mail prices. VAT is only charged on the input to the NPO. As the combined volumes do not change substantially, the VAT and welfare are reasonably stable over the break-even range of cases.

The final three columns of figures in Table 1 relate to the VAT rated monopolist. Here the NPO charges VAT at an assumed rate of $20 \%$ on its services and reclaims the VAT it pays on its inputs. Comparing these three columns with the first three allows us to obtain the impact of changing the VAT status of the NPO from exempt to rated under three different pricing rules. At the (pre-tax) calibration prices of 0.5 for single-piece and 0.4 for bulk mail, the net impact for the NPO's profit of moving to a VAT rated status (as discussed in section 2.1.) is positive. In order to compare with the other columns of Table 1 (all of which have the NPO breaking even), we report in the first of the last three columns the results obtained when we scale down both pre-tax prices by the same percentage compared to the calibrated values reported in the first numerical column. In this case, the post-VAT prices for the single-piece item is higher at 0.574 and bulk mail at 0.459 for $N$ customers, having applied VAT at a rate of $20 \%$. However, for $R$ customers the effective bulk mail price decreases to 0.382 as those customers can reclaim the VAT applied to the price. Where the prices paid increase the demand reduces - to $1.94 \mathrm{bn}$ items for singlepiece and from $4.00 \mathrm{bn}$ to $3.76 \mathrm{bn}$ items for VAT exempt bulk mail customers. Volumes increase from $4.00 \mathrm{bn}$ to $4.07 \mathrm{bn}$ for VAT rated customers of bulk mail. The reduction in total volume reduces the NPO's input VAT but this is more than offset by the VAT recovered through prices to yield net VAT receipts of $0.566 \mathrm{bn}$. Relative to the calibration in the first column of Table 1, total customer surplus is much lower. The increase in (weighted) VAT receipts more than compensates for the loss in total consumer surplus within the calibration.

The second best welfare maximizing result for the VAT rated monopolist is shown in the fifth column of Table 1 and may be compared to the VAT exempt monopolist in the second column. The post-VAT single-piece price of the VAT rated NPO at 0.688 is $12 \%$ more than the single-piece price of the VAT exempt NPO of 0.615 - the single-piece price increases less than the VAT rate of $20 \%$. In other words, just over $60 \%$ of the tax is borne by consumers in the form of a higher after-tax price.

The combined effect of the tax on both types of bulk mail customers jointly is that less of the tax is shifted forward to bulk mail customers overall than in the case of single-piece customers. This is in line with economic theory in that, in a perfectly competitive economy, the higher the elasticity of demand, the smaller the fraction of a tax on transactions that is borne by customers. However, the position is complicated by the different tax status of the two classes of bulk mail customers, those that are VAT rated and those that are not, which results from them facing, inclusive of the tax, significantly different effective prices for bulk mail. VAT rated customers, although charged the tax, actually face lower prices than without the tax (by $3 \%$ from 0.371 to 0.359 ). This unusual 
situation arises inter alia because, first, the cost base of the NPO is lowered by its ability to reclaim input tax so helping to lower the pre-tax price and, secondly, that a VAT rated bulk mail customer itself can reclaim as input tax the VAT levied by the NPO. By contrast, for VAT exempt bulk mail customers the post-VAT bulk mail price of the VAT rated NPO at 0.430 is $16 \%$ more than the bulk mail price of the VAT exempt NPO of 0.371 . A larger percentage of the tax $(80 \%)$ is borne by $N$ consumers of bulk mail than by $(N)$ consumers of single-piece mail. But the weighted average across both types of bulk mail customers is just over $30 \%$, less than single-piece customers.

Comparison of the second and fifth columns of Table 1 also shows that the total consumer surplus of the VAT exempt NPO at $6.510 \mathrm{bn}$ is significantly higher than that for the VAT rated NPO of $6.187 \mathrm{bn}$. At the calibration values set out in section 3 , this means that VAT rated bulk mail customers gain less than VAT exempt customers lose from the change of VAT status of the NPO (both single-piece and bulk mail exempt customers lose). However, when VAT receipts are added to the total consumer surplus and profit and multiplied by 1.3 to reflect social welfare, the welfare of the VAT exempt NPO at $6.799 \mathrm{bn}$ is marginally less than that for the VAT rated NPO of $6.825 \mathrm{bn}$. Under such assumptions, the movement from a VAT exempt to VAT rated NPO would reduce the economic welfare of postal consumers, but within the model framework this would be offset by the VAT receipts to the VAT authority such that the welfare would be very marginally more in the case of the VAT rated NPO for society as a whole at the cost of public funds assumed of 0.3. Finally, the Lagrange multiplier of the NPO's zero-profit constraint is larger when the NPO is VAT rated, but remains smaller than the exogenous cost of public funds.

Moving to the minimum single-piece mail price consistent with the NPO breaking even, and comparing the third and sixth columns of Table 1, we obtain a second tax incidence result, with roughly $75 \%$ of the $20 \%$ VAT rate borne directly by single-piece mail consumers in the form of a higher after-tax price. Note that the NPO can break-even with smaller pre-tax prices when VAT rated because then it would be able, under the alternative tax regime, to recover input tax. As they care only about pre-tax prices, VAT rated customers benefit from this move, while VAT exempt customers suffer from higher after-tax prices. Total surplus is lower than in the third column of Table 1, but the sum of surplus and of weighted VAT proceeds is larger than in the third column of Table 1.

We now summarize the main impacts from our model of changing the VAT status of the monopoly NPO from exempt to rated at the calibration values set out in section 3 .

Result 11 A move from VAT exempt to VAT rated increases the monopoly NPO's profit if pre-tax prices stay at their calibration level. For the three pricing rules we have studied (equi-proportional mark-up, Ramsey and minimum single-piece mail price), moving the NPO's VAT status from exempt to rated has the same qualitative impact: VAT exempt customers lose (because of higher after-tax prices) while VAT rated customers benefit (from lower pre-tax prices). In terms of tax incidence, as expected from economic theory, only part of the tax is shifted forward to customers. Total customers' surpluses decrease (that is, VAT exempt customers lose more than VAT rated customers gain). VAT proceeds increase (that is, the VAT proceeds paid by VAT exempt customers are larger than the VAT proceeds previously paid by the NPO on its inputs) and, when weighted by the cost of public funds, increase more than the decrease in customers surplus, so that total welfare is higher when the NPO is VAT rated than when it is VAT exempt. 


\subsection{Competition with access only}

Some of the results of the NPO offering access entry are similar to those of the monopolist NPO. The first two columns of figures in Table 2 show the results of the NPO offering an access service to entrants for a VAT exempt NPO. The first column shows the welfare maximizing results which for the single-piece and bulk mail $N$ customers are almost identical to those in column 2 of Table 1 . However, in this case the NPO's access service leads entrants to undercut the NPO's bulk mail price for $R$ customers, as these customers are able to recover the VAT charged by the entrant. The VAT charged by the entrant cannot be recovered by the $N$ customers and in this case the entrants' price exceeds the NPO's bulk mail price. Some of the $R$ customers' volumes transfer from the NPO to entrants and the lower price offer results in some overall growth in demand. This results in a marginal improvement in total consumer surplus and total welfare for the welfare maximizing access entry case in column 1 of Table 2 relative to that of the NPO monopolist in column 2 of Table 1.

The second column in Table 2 shows the minimum $q$ with access entry and the VAT exempt NPO. When compared to the third column in Table 1, the results of minimum $q$ in column 2 of Table 2 show higher single-piece and bulk mail prices at 0.480 and 0.420 respectively. The price ranges within which break-even occurs are slightly narrower in the presence of access entry and the difference in total consumer surplus and total welfare measures between the minimum $q$ and welfare maximizing case increase with the access entry. The access price at 0.210 in this case is marginally lower than that in the welfare maximizing case of column 1 in Table 2.

The last two columns of figures in Table 2 show the results of the NPO with access entry for the VAT rated NPO. The first of these columns shows the welfare maximizing results which for the single-piece customers are almost identical to those in column 5 of Table 1 for the calibration reported in Section 3. For bulk mail customers, the $R$ customers compare the pre-VAT prices of the NPO and entrants, and the $N$ customers compare the post-VAT prices. In both cases the entrants' prices are less than the NPO's prices, and this leads to some of the NPO's volumes for both the $R$ and $N$ customers to switch to the entrants. In this case, the volumes switching are similar for $R$ and $N$ customers, but more generally the volume switch is greater where the price difference between NPO and entrants is greater.

Result 2 2Changing the VAT status of the NPO from exempt to rated has the same qualitative impact under access-based competition as under monopoly: VAT exempt customers lose more than VAT rated customers gain, but total welfare increases thanks to the increase in (weighted) VAT proceeds. In that sense, the observations summarized in Result 1 are robust to the introduction of access-based competition in the postal sector.

\begin{tabular}{|l|c|c|c|c|}
\hline & \multicolumn{2}{|c|}{ VAT exempt NPO } & \multicolumn{2}{c|}{ VAT rated NPO } \\
\hline & $\begin{array}{c}\text { Welfare } \\
\text { maximizing }\end{array}$ & $\begin{array}{c}\text { Minimum } \\
\mathrm{q}\end{array}$ & $\begin{array}{c}\text { Welfare } \\
\text { maximizing }\end{array}$ & $\begin{array}{c}\text { Minimum } \\
\mathrm{q}\end{array}$ \\
\hline Single-piece & $(\lambda=0.16)$ & & $(\lambda=0.195)$ & \\
\hline Pre-VAT price & 0.614 & 0.480 & 0.574 & 0.469 \\
\hline
\end{tabular}




\begin{tabular}{|c|c|c|c|c|}
\hline $\begin{array}{l}\text { Post-VAT } \\
\text { price }\end{array}$ & 0.614 & 0.480 & 0.689 & 0.562 \\
\hline Volume & 1.909 & 2.016 & 1.848 & 1.950 \\
\hline \multicolumn{5}{|l|}{ Bulk mail } \\
\hline Pre-VAT price & 0.371 & 0.420 & 0.359 & 0.409 \\
\hline $\begin{array}{l}\text { Post-VAT } \\
\text { price }\end{array}$ & 0.371 & 0.420 & 0.431 & 0.490 \\
\hline Volume $\mathrm{N}^{15}$ & 4.117 & 3.793 & 3.528 & 2.460 \\
\hline Volume $\mathrm{R}^{16}$ & 3.643 & 2.548 & 3.529 & 2.639 \\
\hline \multicolumn{5}{|l|}{ Entry } \\
\hline Pre-VAT price & 0.369 & 0.354 & 0.351 & 0.349 \\
\hline $\begin{array}{l}\text { Post-VAT } \\
\text { price }\end{array}$ & 0.442 & 0.425 & 0.421 & 0.418 \\
\hline Volume N & 0.000 & 0.172 & 0.463 & 1.571 \\
\hline Volume R & 0.633 & 1.832 & 0.845 & 1.768 \\
\hline \multicolumn{5}{|l|}{ Access } \\
\hline Price & 0.224 & 0.210 & 0.207 & 0.204 \\
\hline $\begin{array}{l}\text { Net VAT } \\
\text { receipts }\end{array}$ & 0.221 & 0.215 & 0.557 & 0.527 \\
\hline $\begin{array}{l}\text { Total } \\
\text { consumer } \\
\text { surplus }{ }^{17}\end{array}$ & 6.523 & 6.459 & 6.198 & 6.116 \\
\hline Welfare & 6.810 & 6.755 & 6.846 & 6.758 \\
\hline
\end{tabular}

Table 2: Allocations with access entry ${ }^{18}$

Are these results robust to modifications of the calibration assumptions? We have performed the same numerical simulations ${ }^{19}$ as in Tables 1 and 2 while changing three assumptions of the model: decreasing the cost of public funds $\mu$ from 0.3 to 0.2 , increasing the share of costs subject to VAT (that is, increasing $\alpha_{F}$ from 0.4 to 0.5 and $\alpha^{I}$ from 0.2 to 0.3 ) and finally lowering the VAT rate $t$ from $20 \%$ to $10 \%$. Changing one assumption at a time, we obtain the same qualitative features as those exposed in Result 1, with one very intuitive exception. When $\mu$ is lower, it is not always the case that total

\footnotetext{
${ }^{15} \mathrm{~N}=$ non VAT rated or VAT exempt customers

${ }^{16} \mathrm{R}=\mathrm{VAT}$ rated customers

${ }^{17}$ Both NPO and entrants profits are zero by assumption.

${ }^{18}$ Prices are expressed in $€$, volumes in billion items, VAT receipts, surplus and welfare in billion euros.

${ }^{19}$ Results available upon request from the authors.
} 
welfare is higher when the NPO is VAT rated, since the increase in VAT proceeds is not enough to counter-balance the decrease in (VAT exempt) customer surplus.

\section{Conclusion}

In this paper, we have looked at the impact of the VAT status of the NPO and customers on the optimal pricing of bulk mail, single-piece mail and access. We have developed a model where single-piece mail is offered only by the NPO while bulk mail is offered either by the NPO alone or by entrants as well. Beyond analytical determination of the optimal Ramsey prices we have considered two other pricing rules; namely equiproportional markups and minimizing single-piece prices. We have calibrated our model and resorted to numerical simulations in order to help assess the possible impact of changes in VAT status on volumes, consumer surplus and VAT proceeds.

In our model, the after tax price of the VAT rated NPO increases by less than the full amount of the VAT. Further, we have shown that a move from a VAT exempt to a VAT rated NPO benefits the VAT rated bulk mail customers and the VAT authority. Additionally, a move from a VAT exempt to a VAT rated NPO is detrimental to both the non VAT rated bulk mail customers and the single-piece customers and significantly increases the single-piece price. Overall the consumer surplus in the postal sector is lower in the case of a VAT rated NPO, but this may be offset when the receipts to the VAT authority are included and scaled within the total welfare measure. The key issue driving relative welfare results is then the cost of public funds. If this cost is high, a higher global welfare level is attained with a VAT rated NPO. If the cost of public funds is low, then the reduced price for VAT exempt customers makes VAT exempt status for the PO desirable from a welfare perspective.

Sensitivity testing of our calibration values indicates that these results appear to be robust to a range of plausible alternative values. Additionally, in a sequel to this paper (De Donder et al (2009)) we concentrate exclusively on numerical results (based on the same calibration assumptions as here) and we show that the qualitative results outlined in the previous paragraphs are robust to the introduction of both the possibility for entrants to bypass the incumbent's delivery network and of a lower VAT rate on single-piece mail.

Our model does not take account of the potential for VAT rated bulk mail customers to create additional business and VAT receipts through reclaiming any VAT on postal services and conversely for VAT exempt customers. This could be included in the analysis as a further extension. Another area of potential extension includes consideration of a budget constraint for government whereby the sum of profit and VAT receipts is the same for both the VAT exempt and VAT rated NPO. Hence, there is scope to develop the model presented in this paper to explore further the consequences of alternative VAT regimes within the postal sector.

\section{$6 \quad$ References}

Armstrong, M. (2002) "The Theory of Access Pricing and Interconnection," in M. Cave et al (ed.), Handbook of Telecommunication, Volume 1, North-Holland, Amsterdam. 
Auerbach, Alan J., and James R. Hines Jr. (2001) "Taxation and Economic Efficiency," in Alan J. Auerbach and Martin Feldstein (ed.)., Handbook of Public Economics, Volume 3, North-Holland: Amsterdam.

De Donder, P. (2006) "Access Pricing in the Postal Sector: Theory and Simulations," Review of Industrial Organization, 28: 307-326.

De Donder, P., H. Cremer, P. Dudley and F. Rodriguez (2006) "Pricing and Welfare Implications of Alternative Approaches to Setting Price Controls in the Postal Sector," in M.A. Crew and P.R. Kleindorfer (ed.), Progress toward Liberalization of the Postal and Delivery Sector, Springer: New York.

De Donder, P., H. Cremer, P. Dudley and F. Rodriguez (2009) "Some Welfare and Pricing Implications of Alternative Regimes for Value Added Taxation in Postal Services," in M.A. Crew and P.R. Kleindorfer (ed.), Progress in the Competitive Agenda in the Postal and Delivery Sector, Edward Edgar: Cheltenham.

Panzar, J. (2004) "Combining Liberalization and Unbundling Policies in Postal Markets," mimeo, Northwestern University and University of Auckland.

\section{$7 \quad$ Appendix}

\subsection{Optimal pricing formulas with VAT exempt NPO}

We first look at the case where the NPO is VAT exempt. Its total cost of providing $x$ units of single-piece mail, $y^{I}$ units of bulk mail and of delivering $y^{E}$ units of entrants' bulk mail on their behalf is given by

$$
\begin{aligned}
C_{N}^{I}\left(x, y^{I}, y^{E}\right)= & F\left(1+\alpha_{F} t\right)+\left(1+\alpha^{I} t\right)\left[\left(c_{x}+d^{I}\right) x\right. \\
& \left.+\left(c_{y}^{I}+d^{I}\right) y^{I}+d^{I} y^{E}\right] .
\end{aligned}
$$

Its (net of tax) profit is then given by

$$
\begin{array}{r}
\Pi_{N}^{I}\left(q, p^{I}, a\right)=\quad q x(q)+p^{I} y^{I}\left(p^{I}, p^{E}\right)+a y^{E}\left(p^{I}, p^{E}\right) \\
-C_{N}^{I}\left(x(q), y^{I}\left(p^{I}, p^{E}\right), y^{E}\left(p^{I}, p^{E}\right)\right)
\end{array}
$$

where $y^{I}\left(p^{I}, p^{E}\right)=y_{N}^{I}\left(p^{I}, p^{E}(1+t)\right)+y_{R}^{I}\left(p^{I}, p^{E}\right)$ and $y^{E}\left(p^{I}, p^{E}\right)=y_{R}^{E}\left(p^{I}, p^{E}\right)+y_{N}^{E}\left(p^{I}, p^{E}(1+t)\right)$.

The (second-best) optimization problem is given by 


$$
\begin{aligned}
\max _{q, p^{I}, a} W_{N}= & C S_{x}(q)+C S_{N}\left(p^{I}, p^{E}(1+t)\right)+C S_{R}\left(p^{I}, p^{E}\right) \\
& +\Pi_{N}^{I}\left(q, p^{I}, a\right)+(1+\mu) V A T_{N}\left(q, p^{I}, p^{E}\right)
\end{aligned}
$$

such that $\Pi_{N}^{I}\left(q, p^{I}, a\right) \geq 0$, [Lagrange multiplier: $\left.\lambda\right]$

where $C S_{N}\left(p^{I}, p^{E}(1+t)\right)$ and $C S_{R}\left(p^{I}, p^{E}\right)$ are net consumer surpluses when the two types of bulk mail products are available at before-tax prices of $p^{I}$ and $p^{E}$ and where the amount of VAT proceeds paid by VAT exempt agents is denoted by

$$
\begin{array}{rl}
\operatorname{VAT}_{N}\left(q, p^{I}, p^{E}\right)=t & t \alpha_{F} F+t \alpha^{I}\left[\left(c_{x}+d^{I}\right) x(q)\right. \\
& +\left(c_{y}^{I}+d^{I}\right)\left(y_{N}^{I}\left(p^{I}, p^{E}(1+t)\right)+y_{R}^{I}\left(p^{I}, p^{E}\right)\right) \\
& \left.+d^{I}\left(y_{R}^{E}\left(p^{I}, p^{E}\right)+y_{N}^{E}\left(p^{I}, p^{E}(1+t)\right)\right)\right] \\
& +t p^{E} y_{N}^{E}\left(p^{I}, p^{E}(1+t)\right) .
\end{array}
$$

The optimality equation for the single-piece mail price is not affected by the presence of entrants and is thus given by (2). As for the bulk mail price $p^{I}$, its optimal value is given by

$$
\frac{p^{I}-\left[\left(1+\frac{\lambda-\mu}{1+\lambda} \alpha^{I} t\right)\left(c_{y}^{I}+d^{I}\right)\right]}{p^{I}}=\frac{\lambda}{1+\lambda} \frac{1}{\varepsilon_{y}}+\sigma^{E I} \frac{a-\left(1+\alpha^{t} t\right) d^{I}}{p^{I}}+\sigma_{N}^{E I} \frac{1+\mu}{1+\lambda} t \frac{p^{E}}{p^{I}}
$$

where

$$
\sigma^{i j}=-\frac{\partial y^{i}\left(p^{I}, p^{E}\right) / \partial p^{j}}{\partial y^{j}\left(p^{I}, p^{E}\right) / \partial p^{j}} \text { and } \sigma_{k}^{i j}=-\frac{\partial y_{k}^{i}\left(p^{I}, p^{E}\right) / \partial p^{j}}{\partial y^{j}\left(p^{I}, p^{E}\right) / \partial p^{j}}
$$

with $i, j \in\{E, I\}, i \neq j$ and $k \in\{N, R\}$ are called displacement ratios (see Armstrong (2002) and De Donder (2006)).

Comparing with the optimal pricing formula under monopoly (equation (3)), we observe two new effects that both concur to increase the optimal $p^{I}$. Both terms have to do with the displacement of demand from NPO's bulk mail towards entrants' bulk mail as $p^{I}$ increases. The first new effect (second term in the RHS of (12)) corresponds to the increase in profit made selling access. The second new effect (last term in the RHS of (12)) corresponds to an increase in VAT proceeds as demand shifts towards the final product of entrants. Observe that in the latter case, only the demand from VAT exempt customers is taken into account.

The optimal value of the access charge $a$ is given by the formula 


$$
\begin{aligned}
& -(1+t) y_{N}^{E}(.)-y_{R}^{E}(.) \\
& +(1+\lambda)\left[p^{I} \frac{\partial y^{I}(.)}{\partial p^{E}}+y^{E}(.)+a \frac{\partial y^{E}(.)}{\partial p^{E}}-\left(1+\alpha^{t} t\right)\left(\left(c_{y}^{I}+d^{I}\right) \frac{\partial y^{I}(.)}{\partial p^{E}}+d^{I} \frac{\partial y^{E}(.)}{\partial p^{E}}\right)\right] \\
& +(1+\mu)\left[\alpha^{t} t\left(\left(c_{y}^{I}+d^{I}\right) \frac{\partial y^{I}(.)}{\partial p^{E}}+d^{I} \frac{\partial y^{E}(.)}{\partial p^{E}}\right)+t y_{N}^{E}(.)+t p^{E} \frac{\partial y_{N}^{E}(.)}{\partial p^{E}}\right]=0 .
\end{aligned}
$$

The complexity of the formula is due to the fact that the access charge impacts the entrants's bulk mail demand coming both from VAT rated and from VAT exempt customers, with different consequences on VAT proceeds and on entrants's prices. To get a better understanding of the formula, we proceed as previously and we assume that the NPO posts two different access charges (denoted by $a_{R}$ and $a_{N}$ ) to entrants depending on the VAT status of their customers. The optimal value for the access charge on the VAT rated market, $a_{R}$, is given by

$$
\begin{aligned}
a_{R} & =d^{I}\left(1+\frac{\lambda-\mu}{1+\lambda} \alpha^{I} t\right)+\sigma_{R}^{I E}\left[p^{I}-\left(c_{y}^{I}+d^{I}\right)\left(1+\frac{\lambda-\mu}{1+\lambda} \alpha^{I} t\right)\right] \\
& +\frac{\lambda}{1+\lambda} \frac{a_{R}}{\varepsilon_{R}^{E}}
\end{aligned}
$$

where $\varepsilon_{i}^{E}$ is the direct price elasticity of entrants's bulk mail demand by VAT rated $(i=R)$ or VAT exempt $(i=N)$ customers. The optimal access price is composed of three components: the delivery cost, a displacement term and the Ramsey mark-up. The intuition for these three elements is given in De Donder (2006). The impact of the VAT status can be seen in the first two terms. Observe that, if $\lambda=\mu$, equation (14) boils down to equation (1) in De Donder (2006). ${ }^{20}$ Increasing the cost of public funds results in a decrease in the weight put on the part of the marginal costs that is subject to input VAT.

The optimal value of the access charge on the VAT exempt market, $a_{N}$, is given by

$$
\begin{aligned}
a_{N} & =d^{I}\left(1+\frac{\lambda-\mu}{1+\lambda} \alpha^{I} t\right)+\sigma_{N}^{I E}\left[p^{I}-\left(c_{y}^{I}+d^{I}\right)\left(1+\frac{\lambda-\mu}{1+\lambda} \alpha^{I} t\right)\right] \\
& +\frac{\lambda+\mu t}{1+\lambda} \frac{a_{N}}{\varepsilon_{N}^{E}}-\frac{1+\mu}{1+\lambda} t p^{E} .
\end{aligned}
$$

There are two additional impacts of increasing $a_{N}$, compared to increasing $a_{R}$. First, the price paid by entrants's VAT exempt customers increases by $(1+t) a_{N}$ rather than by $a_{R}$. Second, the planner cares about VAT proceeds coming from these VAT exempt customers -- but not from VAT rated customers of bulk mail. Observe that the first line of (15) is

\footnotetext{
${ }^{20}$ There is no good $D$ in the current paper, so the third term in the RHS of equation (1) in De Donder (2006) vanishes in our context.
} 
similar to the first line of (14), while the second line contains two differences. The first difference lies in the numerator of the Ramsey mark-up, which goes from $\lambda$ in equation (14) to $\lambda+\mu t$ in equation (15). The second difference takes the form of an additional term in the formula. The first term in the second line of (15) collapses to the corresponding term in (14) only if $\mu=0$ or if $t=0$. The new term in (15) disappears only if $\mu=-1$ (that is, the planner does not care at all for tax proceeds) or if $t=0$. As a consequence, the formulas (15) and (14) are equivalent only in absence of VAT ; that is, if $t=0$.

Since we assume that the same access charge has to be posted irrespective of the VAT status of entrants's customers, the optimal access charge formula is given by the more complex equation (13).

\subsection{Optimal pricing formulas with VAT rated NPO}

We now turn to the case where the NPO is VAT rated. Its total cost is given by

$$
C_{R}^{I}\left(x, y^{I}, y^{E}\right)=F+\left(c_{x}+d^{I}\right) x+c_{y}^{I} y^{I}+d^{I}\left(y^{I}+y^{E}\right)
$$

and its (net of tax) profit is

$$
\begin{aligned}
\Pi_{R}^{I}\left(q, p^{I}, a\right)= & q x(q(1+t))+p^{I} y^{I}\left(p^{I}, p^{E}\right)+a y^{E}\left(p^{I}, p^{E}\right) \\
& -C_{R}^{I}\left(x(q(1+t)), y^{I}\left(p^{I}, p^{E}\right), y^{E}\left(p^{I}, p^{E}\right)\right)
\end{aligned}
$$

with $y^{I}\left(p^{I}, p^{E}\right)=y_{N}^{I}\left(p^{I}(1+t), p^{E}(1+t)\right)+y_{R}^{I}\left(p^{I}, p^{E}\right)$ and $y^{E}\left(p^{I}, p^{E}\right)=y_{R}^{E}\left(p^{I}, p^{E}\right)+y_{N}^{E}\left(p^{I}(1+t), p^{E}(1+t)\right)$.

The Ramsey optimization problem of a VAT rated NPO is given by

$$
\begin{aligned}
\max _{q, p^{I}, a} W_{R}= & C S_{x}(q(1+t))+C S_{N}\left(p^{I}(1+t), p^{E}(1+t)\right) \\
& +C S_{R}\left(p^{I}, p^{E}\right)+\Pi_{R}^{I}\left(q, p^{I}, a\right)+(1+\mu) V A T_{R}\left(q, p^{I}, p^{E}\right)
\end{aligned}
$$

such that $\Pi_{R}^{I}\left(q, p^{I}, a\right) \geq 0$, [Lagrange multiplier: $\left.\lambda\right]$,

with

$$
\operatorname{VAT}_{R}\left(q, p^{I}, p^{E}\right)=t\left[q x(q(1+t))+p^{I} y_{N}^{I}\left(p^{I}(1+t), p^{E}(1+t)\right)+p^{E} y_{N}^{E}\left(p^{I}(1+t), p^{E}(1+t)\right)\right] \text {. }
$$

The formula for the optimal single-piece mail price is not affected and still given by (2).

As for the other two prices (access charge and bulk mail price), we proceed as before and assume that the NPO can post different prices for VAT rated customers $\left(a_{R}, p_{R}^{I}\right)$ and for VAT exempt customers $\left(a_{N}, p_{N}^{I}\right)$. The optimal prices for VAT rated customers are given by 


$$
p_{R}^{I}=c_{y}^{I}+d^{I}+\sigma_{R}^{E I}\left(a-d^{I}\right)+\frac{\lambda}{1+\lambda} \frac{p_{R}^{I}}{\varepsilon_{R}}
$$

and

(18) $a_{R}=d^{I}+\sigma_{R}^{I E}\left[p^{I}-c_{y}^{I}-d^{I}\right]+\frac{\lambda}{1+\lambda} \frac{a_{R}}{\varepsilon_{R}^{E}}$.

We refer the reader to De Donder (2006) for an in-depth interpretation of these formulas, from which tax considerations (including $\mu$ ) are absent.

The optimal prices for VAT exempt customers are given by

$$
p_{N}^{I}\left(1+\frac{1+\mu}{1+\lambda} t\right)=c_{y}^{I}+d^{I}+\sigma_{N}^{E I}\left(a-d^{I}+\frac{1+\mu}{1+\lambda} t p_{N}^{E}\right)+\frac{\lambda+\mu t}{1+\lambda} \frac{p_{N}^{I}}{\varepsilon_{N}}
$$

and

(20) $a_{N}=d^{I}+\frac{1+\mu}{1+\lambda} t p_{N}^{E}+\sigma_{N}^{I E}\left[p^{I}\left(1+\frac{1+\mu}{1+\lambda} t\right)-c_{y}^{I}-d^{I}\right]+\frac{\lambda+\mu t}{1+\lambda} \frac{a_{N}}{\varepsilon_{N}^{E}}$.

Compared with formulas (17) and (18), equations (19) and (20) are modified in a way now familiar to the reader.

We will also consider the objective of minimizing the single-piece price $q$ while allowing the NPO to break-even. Compared to the optimization program (10), we have an additional degree of freedom in the setting of the access charge. We then impose that both the access charge and the bulk mail price exhibit the same mark-up $m$ over marginal $\operatorname{cost}^{21:}$

$$
\begin{aligned}
& \min q \text { such that } \Pi_{i}^{I}\left(q, p^{I}, a\right) \geq 0, \\
& p^{I}=(1+m)\left(c_{y}^{I}+d^{I}\right), \\
& a=(1+m) d^{I} .
\end{aligned}
$$

\footnotetext{
${ }^{21}$ As in problem (10), we also impose the constraint $q \geq p^{I}+k$ that happens to be binding in the results reported in section 4 .
} 